\title{
Survei Pengetahuan Orang Tua melalui Kegiatan Sekolah Keluarga Balita (SKB) dengan Online Learning
}

\author{
Ari Indra Susanti ${ }^{1 *}$, Dani Ferdian ${ }^{1}$, Eka Noyan Nur Annisa ${ }^{2}$, Raya Faiha Calista ${ }^{2}$ \\ ${ }^{1}$ Departemen IImu Kesehatan Masyarakat, Fakultas Kedokteran, Universitas Padjadjaran \\ ${ }^{2}$ Pasca Sarjana Fakultas Kesehatan Masyarakat Universitas Indonesia \\ *Email korespondensi: ari.indra@unpad.ac.id
}

\begin{abstract}
Article Info
ABSTRACT

Article history:

Submitted: 2020-06-05

Accepted: 2020-08-16

Published: 2020-08-30

Keywords:

Knowledge;

Online learning; First

1000 Day of Life

Health education in the digital era requires one social media, namely WhatsApp as an information media that is considered effective and efficient. Thus, parents get health education through WhatsApp in the Sekolah Keluarga Balita (SKB) online learning activities with the agreed time. This study aims to determine the knowledge of parents about the First 1000 Days of Life (HPK) through the SKB online learning that used WhatsApp. The research method used description with a cross-sectional approach. This research was conducted in March 2020 among parents of toddlers living in the fostered villages of Kampung Bestari Astra (KBA) as many as 150 people. The sampling technique was used accidental sampling. This questionnaire was given to the respondent in the form of bit.ly/ (google form). This questionnaire was filled out by respondents before being given a health education video. Data analysis using univariate have presented in the form of a frequency distribution table. The results showed that most participants in the Joint Decree were 135 people, with the age of 20-35 years as many as 60 people, and 78 parents were unfavorable knowledge. The conclusion in this study that some parents aged 20-35 years have less knowledge about the First 1000 Days of Life (HPK) so that health education is needed in a Toddler Family School (SKB) online using WhatsApp.
\end{abstract}

Kata kunci:
Pengetahuan; Online
Learning; 1000 HPK

Seiring perkembangan teknologi saat ini, maka pendidikan kesehatan di era digital memerlukan salah satu media sosial, yaitu whatsapp sebagai media informasi yang dianggap efektif dan efisien. Dengan demikian, orang tua mendapatkan pendidikan kesehatan melalui whatsapp dalam kegiatan Sekolah Keluarga Balita (SKB) secara online learning dengan waktu yang telah disepakati. Penelitian ini bertujuan untuk mengetahui pengetahuan orang tua tentang 1000 Hari Pertama Kehidupan (HPK) melalui Program Sekolah Keluarga Balita (SKB) secara online learning yang menggunakan whatsapp. Metode penelitian yang digunakan adalah deskripsi dengan pendekatan cross sectional. Penelitian ini dilakukan pada bulan Maret 2020 pada orang tua balita yang tinggal di desa binaan Kampung Bestari Astra (KBA) sebanyak 150 orang. Teknik pengambilan sampel menggunakan accidental sampling. Pengambilan data dilakukan dengan memberikan kuesioner kepada reposnden dalam bentuk bit.ly/ (google form) sebelum diberikan pendidikan kesehatan tentang 1000 HPK. Analisis data pada penelitian ini menggunakan univariat yang disajikan dalam bentuk tabel distribusi frekuensi. Hasil penelitian didapatkan bahwa peserta kegiatan SKB paling banyak perempuan sebanyak 135 orang, dengan usia 20-35 tahun sebanyak 60 orang, dan pengetahuan orang tua yang kurang sebanyak 78 orang. Simpulan dalam penelitian ini bahwa sebagian orang tua dengan usia 20-35 tahun memiliki pengetahuan yang kurang tentang 1000 HPK sehingga diperlukan pendidikan kesehatan dalam Sekolah Keluarga Balita (SKB) secara online menggunakan whatsapp

(c) (1) (2) This work is licensed under a Creative Commons Attribution 4.0 International License

DOI: $10.33860 / j b c . v 2 i 3.91$ 


\section{PENDAHULUAN}

Saat ini, dunia telah memasuki era revolusi industri 4.0 yang ditandai dengan semakin berkembangnya teknologi sehingga semua aktivitas dilakukan serba digital dan serba internet. ${ }^{1}$ Dengan makin berkembangnya penggunaan internet yang demikian pesat, maka arus pertukaran informasi dapat terjadi dalam hitungan detik terutama melalui media sosial. Dengan demikian, dalam berkomunikasi maupun menyebarkan informasi melalui media sosial harus berhati-hati, karena pemerintah telah mengeluarkan Undang-Undang Informasi dan Transaksi Elektronik (UU ITE). ${ }^{2}$ UU ITE mengatur berbagai perlindungan hukum atas kegiatan yang memanfaatkan internet sebagai medianya, baik transaksi maupun pemanfaatan informasinya. ${ }^{3}$

Kebutuhan informasi kesehatan yang akurat dan terkini semakin dibutuhkan seiring perkembangan teknologi informasi. Media sosial telah menunjukkan perannya dalam upaya promosi kesehatan di dunia. Media sosial berkontibusi positif terhadap upaya promosi kesehatan. Namun, beberapa kelemahan, diantaranya: kurangnya penjangkauan terhadap audien pasif, informasi palsu dan tidak akurat, kurangnya interaksi dengan audien, serta keterbatasan kemampuan profesional kesehatan memanfaatkan media sosial sehingga tidak menjamin keberlanjutan program. Profesional bidang kesehatan perlu merancang model promosi kesehatan berbasis media sosial dengan mengintegrasikan media sosial dengan strategi promosi kesehatan serta strategi komunikasi kesehatan. ${ }^{4}$

Menurut Menteri Kesehatan bahwa upaya perbaikan gizi pada 1000 hari kehidupan, telah ditetapkan beberapa kebijakan, diantaranya: meningkatkan cakupan dan kualitas pelayanan kehamilan dan persalinan, melakukan sosialisasi dan pemantauan pelaksanaan UU nomor 36/2009 tentang Kesehatan dan PP nomor 33/2012 tentang Pemberian ASI Eksklusif untuk meningkatkan cakupan dan kualitas pelayanan gizi dan kesehatan melalui penyediaan dukungan tenaga kesehatan, penyediaan obat gizi dan suplementasi yang cukup, meningkatkan kegiatan edukasi kesehatan dan gizi melalui budaya perilaku hidup bersih dan sehat, serta dengan meningkatkan komitmen berbagai pemangku kepentingan terutama lintas sektor, dunia usaha serta masyarakat untuk bersama-sama memenuhi kebutuhan pangan tingkat keluarga. ${ }^{5}$

Saat ini terjadi wabah pandemi Covid-19 maka perlu memberikan pendidikan kesehatan kepada keluarga untuk meningkatkan kesadaran dalam kualitas hidup terutama pada bayi dan balita. Kondisi ini menyebabkan masyarakat harus melakukan semua aktivitas di rumah sehingga di inisiasi membentuk Sekolah Keluarga Balita (SKB) secara online learning yang menggunakan whatsapp sebagai salah satu media sosial. Berdasarkan hasil penelitian yang dilakukan oleh A O'Higgins et.al, bahwa ibu hamil yang menggunakan smartphone untuk memperoleh informasi tentang kehamilan sebanyak $59 \%$. Sedangkan ibu hamil yang menggunakan media sosial untuk memperoleh informasi tentang kehamilan sebanyak $67 \% .{ }^{6} \mathrm{Hal}$ tersebut, sejalan dengan penelitian yang dilakukan oleh Nopryan Ekadinata dkk, bahwa 40\% kader menggunakan whatsapp sebagai media komunikasi selama 3 tahun. $^{7}$

Dengan demikain, penelitian ini bertujuan untuk mengetahui pengetahuan orang tua tentang 1000 Hari Pertama Kehidupan (HPK) melalui Kegiatan Sekolah Keluarga Balita (SKB) secara online learning yang menggunakan whatsapp. 


\section{METODE}

Penelitian ini merupakan studi deskriptif dengan desain cross-sectional. Penelitian ini dilakukan pada bulan Maret 2020 kepada orang tua bayi/ balita yang berada di wilayah Kampung Berseri Astra (KBA)/Desa Sejahtera Astra (DSA) sebanyak 150 orang. Teknik pengambilan sampel menggunakan accidental sampling. Pengambilan data dilakukan dengan memberikan kuesioner kepada responden sebelum diberikan pendidikan kesehatan tentang 1000 HPK pada kegiatan Sekolah Keluarga Balita (SKB) menggunakan grup WhatsApp. Kriteria dalam penelitian ini adalah orang tua bayi/ balita yang bergabung ke dalam grup WhatsApp dan mengisi kuesioner secara lengkap.

Data diperoleh dengan pengisian kuesioner yang disebar melalui google form dan pengisian kuesioner dilakukan sebelum peserta mendapat video kesehatan 1000 HPK. Kemudian, data dianalisis dengan analisis univariat untuk memperoleh gambaran distribusi frekuensi karakteristik peserta SKB dan tingkat pengetahuan peserta SKB mengenai 1000 HPK.

\section{HASIL PENELITIAN}

Hasil penelitian dapat disajikan sebagai berikut:

Tabel 1. Peserta Kegiatan Sekolah Keluarga Balita (SKB) berdasarkan jenis kelamin dan umur

\begin{tabular}{lcc}
\hline Jenis Kelamin Peserta & Jumlah & Persentase (\%) \\
\hline$\quad$ Perempuan & 135 & 90,0 \\
$\quad$ Laki-laki & 15 & 10,0 \\
Usia & & \\
20-35 tahun & 60 & 40,0 \\
>35 tahun & 90 & 60,0 \\
\hline
\end{tabular}

Sumber: Data Primer, 2020

Dari hasil penelitian, terlihat pada tabel 1 bahwa peserta kegiatan Sekolah Keluarga Balita (SKB) paling banyak adalah perempuan sebanyak $90 \%$, sedangkan peserta laki-laki hanya $10 \%$. Sedangkan peserta SKB paling banyak berada pada usia $>35$ tahun sebanyak 40\%, sedangkan peserta dengan rentang usia 20-35 tahun sebanyak $60 \%$.

Tabel 2. Distribusi Jawaban Pengetahuan Responden tentang tentang 1000 HPK

\begin{tabular}{|c|c|c|c|c|}
\hline \multirow{2}{*}{ Item pertanyaan pengetahuan } & \multicolumn{2}{|c|}{ Benar } & \multicolumn{2}{|c|}{ Salah } \\
\hline & $\mathbf{n}$ & $\%$ & $\mathbf{n}$ & $\%$ \\
\hline 1. Pengertian 1000 hari pertama kehidupan. & 98 & 64,5 & 54 & 35,3 \\
\hline 2. Pengertian stunting. & 130 & 85,5 & 22 & 14,5 \\
\hline 3. Pengukuran untuk mengetahui anak stunting atau tidak & 61 & 40,1 & 91 & 59,9 \\
\hline $\begin{array}{l}\text { 4. Akibat kekurangan gizi pada } 1000 \text { hari pertama kehidupan } \\
\text { terhadap perkembangan organ metabolic. }\end{array}$ & 22 & 14,5 & 130 & 85,5 \\
\hline $\begin{array}{l}\text { 5. } 1000 \text { HPK merupakan jendela kritis pertumbuhan dan } \\
\text { perkembangan. }\end{array}$ & 86 & 56,5 & 66 & 43,4 \\
\hline 6. Faktor penyebab langsung masalah gizi. & 7 & 4,6 & 145 & 95,4 \\
\hline 7. Faktor penyebab tidak langsung masalah gizi. & 52 & 34,2 & 100 & 65,8 \\
\hline
\end{tabular}




\begin{tabular}{|c|c|c|c|c|}
\hline \multirow{2}{*}{ Item pertanyaan pengetahuan } & \multicolumn{2}{|c|}{ Benar } & \multicolumn{2}{|c|}{ Salah } \\
\hline & $\mathbf{n}$ & $\%$ & $\mathbf{n}$ & $\%$ \\
\hline $\begin{array}{l}\text { 8. program spesifik (sektor kesehatan) dalam } \\
\text { penanggulangan permasalahan gizi pada } 1000 \text { hari } \\
\text { pertama kehidupan. }\end{array}$ & 29 & 19,1 & 123 & 80,9 \\
\hline $\begin{array}{l}\text { 9. program sensitif (sektor non kesehatan) dalam } \\
\text { penanggulangan permasalahan gizi pada } 1000 \text { hari } \\
\text { pertama kehidupan. }\end{array}$ & 73 & 48,0 & 79 & 52,0 \\
\hline $\begin{array}{l}\text { 10. Akibat kekurangan gizi pada } 1000 \text { hari pertama kehidupan } \\
\text { terhadap pertumbuhan fisik. }\end{array}$ & 103 & 67,8 & 49 & 32,2 \\
\hline
\end{tabular}

Berdasarkan tabel 2 diketahui, pertanyaan yang paling banyak dijawab benar adalah tentang pengertian stunting yaitu sebanyak $85,5 \%$, sedangkan pertanyaan yang paling banyak dijawab salah adalah tentang faktor penyebab langsung masalah gizi yaitu $95,4 \%$.

Tabel 3. Pengetahuan peserta tentang 1000 HPK pada Kegiatan Sekolah Keluarga Balita (SKB)

\begin{tabular}{|c|c|c|}
\hline Pengetahuan & $\mathbf{n}$ & $\%$ \\
\hline Baik & 72 & 48 \\
\hline Kurang & 78 & 52 \\
\hline Jumlah & 150 & 100 \\
\hline
\end{tabular}

Sumber: Data Primer, 2020

Pada penelitian ini, tingkat pengetahuan dibagi ke dalam 2 kelompok, yaitu pengetahuan baik dan pengetahuan kurang. Dari tabel 3 . terlihat bahwa paling banyak peserta SKB memiliki tingkat pengetahuan kurang sebanyak 78 orang dan peserta dengan tingkat pengetahuan baik sebanyak 72 orang.

\section{PEMBAHASAN}

Salah satu usaha yang dilakukan pemerintah untuk meningkatkan Kesehatan lbu dan Anak dengan memberikan pendidikan kesehatan melalui media sosial. Dengan demikian, media sosial digunakan oleh masyarakat, pasien, dan professional kesehatan sehingga dapat saling berkomunikasi terkait masalah kesehatan. Media sosial dikembangkan sebagai sarana pendidikan kesehatan bagi masyarakat yang mudah dan terjangkau. Hal tersebut, mendorong untuk membuat aplikasi dan mengarahkan masyarakat untuk menggunakan media sosial agar lebih bijak, sehingga mampu merubah perilaku. ${ }^{8}$

Hasil penelitian berdasarkan tabel 1, menunjukkan bahwa perempuan lebih banyak ikut serta, dibandingkan laki-laki dalam kegiatan Sekolah Keluarga Balita (SKB). Hal ini mungkin terjadi karena perempuan memiliki peran secara langsung dalam memelihara kesehatan keluarga dan mempersiapkan makanan bergizi bagi anak dan keluarganya. Terutama pada 1000 HPK, dimana wanita yang sedang mempersiapkan kehamilan perlu mengetahui tentang gizi seimbang sejak sebelum hamil, selama kehamilan, hingga anak berusia dua tahun agar bayi yang lahir terhindar dari masalah kesehatan, terutama masalah gizi. ${ }^{9}$

Umur merupakan salah satu faktor yang dapat menentukan kematangan seseorang dan memengaruhi pengetahuan, sikap, maupun tindakan seseorang 10 
Berdasarkan hasil penelitian pada tabel 2. menunjukkan bahwa peserta SKB paling banyak diikuti oleh peserta dengan usia >35 tahun. Pendidikan kesehatan yang diberikan dapat mendukung pengetahuan ibu baik tentang 1000 HPK paling besar dipengaruhi oleh usia 20-35 tahun sehingga dapat mencegah terjadinya kejadian stunting pada balita. ${ }^{11} \mathrm{Hal}$ ini berdasarkan pada asumsi, bahwa orang dewasa yang lebih tua, karena keterbatasan kapasitas memori yang bekerja, sehingga kurang mampu memproses informasi secara efisien dibandingkan dengan orang dewasa yang lebih muda. Namun, ketika orang dewasa yang lebih tua memiliki pengetahuan untuk mengaplikasikan, mereka mungkin dapat menggunakannya dalam pengambilan keputusan untuk meningkatkan efisiensi. ${ }^{12}$

Pengetahuan adalah pemahaman teoritis maupun praktis yang diperoleh melalui pendidikan. Jenis pengetahuan terdiri dari: pengetahuan deklaratif untuk mempelajari tentang konsep dan pengetahuan prosedural untuk mempelajari prosedur atau metode penyelesaian masalah ${ }^{13}$

Berdasarkan hasil penelitian pada tabel 3. didapatkan bahwa peserta SKB sebagian besar memiliki tingkat pengetahuan yang kurang. Kuesioner yang diisi oleh orang tua dari 10 pertanyaan terdapat 7 pertanyaan yang jawabannya salah. Pertanyaan tersebut terkait tentang tanda anak stunting berdasarkan Berat Badan (BB) dan Tinggi Badan (TB), akibat kekurangan gizi pada 1000 hari pertama kehidupan, pentingnya 1000 HPK, faktor penyebab langsung, dan tidak langsung pada masalah gizi. Berdasarkan analisis pada setiap soal yang ditanyakan, peserta paling sedikit menjawab benar pada pertanyaan mengenai faktor penyebab stunting, dampak kekurangan gizi terhadap perkembangan organ metabolik, dan intervensi permasalahan gizi dari sektor non-kesehatan.

Masa 1000 hari pertama kehidupan (HPK) merupakan masa terpenting dalam daur kehidupan manusia. Status gizi pada 1000 HPK akan memengaruhi kualitas kesehatan, intelektual, dan produktivitas pada masa yang akan datang ${ }^{14}$ Selain itu juga, terkait dengan program sektor kesehatan, dan non sektor kesehatan pada 1000 HPK. Kegiatan yang telah dilakukan oleh dinas kesehatan dilanjutkan dengan meningkatkan kerjasama lintas sektor dalam program sensitif 1000 hari pertama kehidupan. Masalah stunting baduta tertinggi pada kelompok umur 12-23 bulan yang berarti pencegahan stunting berfokus pada penguatan program Makanan Pendamping ASI (MP-ASI). ${ }^{15}$

Informasi yang diberikan melalui pendidikan Kesehatan merupakan pesan yang disampaikan memiliki karakteristik isi pesan, yaitu menarik, mudah dimengerti, mudah diterima, dan mudah diingat. ${ }^{16}$ Program promosi dan edukasi kesehatan melalui pengiriman pesan bergambar pada WhatsApp dianggap efektif karena dapat meningkatkan pengetahuan dan kepuasan lebih tinggi dibandingkan pesan teks. ${ }^{7}$

Menurut Edgar Dale bahwa media merupakan integrasi dalam sistem pembelajaran. Namun, efektifitas media tidak dilihat dari seberapa canggihnya media tersebut dalam penggunaannya. Untuk menghindari persepsi yang salah, maka terbentuklah media audio visual sebagai media pembelajaran, yang dalam perkembanganya media tersebut memanfaatkan pengalaman yang kongkrit sebagai model pembelajaran. ${ }^{17}$

Informasi kesehatan melalui gambar berhubungan dengan peningkatan minat belajar dan lebih efektif pada orang dengan tingkat literasi rendah. Gambar edukatif meningkatkan respon emosional dan minat belajar spesifik. Perumusan gambar edukatif yang baik akan berimplikasi positif terhadap penerima pesan pada setiap 
segmentasi usia. Sedangkan, pendidikan kesehatan melalui teks edukatif diterima efektif pada individu dengan tingkat literasi baik serta cenderung tidak berhubungan dengan peningkatan minat belajar penerima pesan.18

Dalam hal ini, orang tua memiliki kepuasan belajar dalam menentukan minat dan upaya eksploratif learner dalam mencapai output pembelajaran secara mandiri dan optimal. Kepuasan belajar merupakan aspek penting yang harus diperhatikan dalam pemberian metode pembelajaran. Metode pembelajaran efektif sangat ditentukan oleh kepuasan belajar dan berbanding lurus dalam pencapaian target pembelajaran. Parameter kepuasan belajar ditentukan oleh aspek konten materi dan metode pencapaian konten. Aspek lain yang perlu dipertimbangkan adalah kapasitas fasilitator, interaktifitas, dan kenyamanan belajar. Metode pembelajaran berbasis WhatsApp memberikan ruang diskusi interaktif. ${ }^{19}$

Dampak dari promosi kesehatan dengan cara pendidikan memang memerlukan waktu lama. Namun, jika perilaku tersebut berhasil diadopsi masyarakat, maka akan langgeng dan akan dilakukan sepanjang hayat. Dengan demikian, media cetak dan media elektronik dapat digunakan sebagai media promosi kesehatan.20

\section{SIMPULAN DAN SARAN}

Sebagian orang tua memiliki pengetahuan yang kurang tentang 1000 Hari Pertama Kehidupan (HPK), terutama mengenai faktor penyebab langsung dan tidak langsung stunting, dampak stunting pada perkembangan organ metabolik, dan intervensi permasalahan gizi dari sekto non-kesehatan. Dengan demikian, diperlukan pendidikan kesehatan dalam Sekolah Keluarga Balita (SKB) secara berkesinambungan dengan berbagai materi yang diperlukan orang tua melalui online menggunakan whatsapp. Selain itu, pemberian pendidikan kesehatan melalui video edukasi maupun gambar dapat dijadikan pilihan sebagai penyebaran informasi sehingga masyarakat diharapkan dapat lebih memahami dan mengetahui lebih jelas setiap informasi yang didapatkan.

\section{UCAPAN TERIMA KASIH}

Tim penulis mengucapakan terima kasih kepada pihak PT Astra Internasional Tbk yang telah membantu terselenggaranya program Sekolah Keluarga Balita (SKB) sehingga hasil kegiatan tersebut dapat di analisis menjadi penelitian.

\section{DAFTAR PUSTAKA}

1. Adiansah W, Setiawan E, Kodaruddin WN, Wibowo H. Person in Environment Remaja Pada Era Revolusi Industri 4.0. Focus: Jurnal Pekerjaan Sosial. 2019;2(1):47-60.

2. Fitriani $Y$. Analisis pemanfaatan berbagai media sosial sebagai sarana penyebaran informasi bagi masyarakat. Paradigma-Jurnal Komputer dan Informatika. 2017;19(2):148-52.

3. Aldyputra ME. Pengaturan penyebaran informasi yang memiliki muatan penghinaan dan/atau pencemaran nama baik dalam Undang-Undang No. 11 Tahun 2008 tentang Informasi dan Transaksi Elektronik: tinjauan yuridis terhadap pasal 27 ayat (3) UndangUndang No. 11 Tahun 2008 tentang Informasi dan Transaksi Elektronik, LN No. 58 Tahun 2008, TLN No. 4843. 2012.

4. Leonita E, Jalinus N. Peran Media Sosial dalam Upaya Promosi Kesehatan: Tinjauan Literatur. INVOTEK: Jurnal Inovasi Vokasional dan Teknologi. 2018;18(2):25-34.

5. Depkes R. Penuhi Kebutuhan Gizi Pada 1000 Hari Pertama Kehidupan. Jakarta: Depkes RI; 2012. 
6. O'Higgins A, Murphy OC, Egan A, Mullaney L, Sheehan S, Turner M. The use of digital media by women using the maternity services in a developed country. Irish medical journal. 2014;107(10):313-5.

7. Ekadinata N, Widyandana D. Promosi kesehatan menggunakan gambar dan teks dalam aplikasi WhatsApp pada kader posbindu. Berita Kedokteran Masyarakat. 2017;33(11):547-52.

8. Nuryati S, Yanti D. Efektifitas Penggunaan Media Sosial Terhadap Peningkatan Pengetahuan Perawatan Nifas Dan Kepatuhan Kunjungan Ulang Pada lbu Nifas Di Kota Bogor. Jurnal Bidan "Midwife Journal. 2017;3(1).

9. Al Rahmad AH. Pengaruh Penyuluhan 1000 Hari Pertama Kehidupan (HPK) pada Pasangan Usia Subur di Perkotaan dan Perdesaan. Jurnal Kesehatan. 2019;10(1):147-52.

10. Gigi K. Gambaran Pengetahuan Orang Tua terhadap Pencegahan Primer Karies pada Anak Usia PRA Sekolah 3-5 Tahun di Tk Kemala Bhayangkari 20 Kab. Pangkep.

11. Susanti AI. Upaya Promotif dan Preventif tentang 1000 Hari Pertama Kehidupan untuk Mencegah Stunting pada Balita. Jurnal Pengabdian Masyarakat Al-Irsyad (JPMA). 2019:92-9.

12. Soederberg Miller LM. Age differences in the effects of domain knowledge on reading efficiency. Psychology and aging. 2009;24(1):63.

13. Handayani L, Kosnin AM, Jiar YK. Breastfeeding education in term of knowledge and attitude through mother support group. Journal of education and Learning. 2012;6(2):65-72.

14. Rahmawati W, Wirawan NN, Wilujeng CS, Fadhilah E, Nugroho FA, Habibie IY, et al. Gambaran Masalah Gizi pada 1000 HPK di Kota dan Kabupaten Malang (Illustration of Nutritional Problem in the First 1000 Days of Life in Both City and District of Malang, Indonesia). Indonesian Journal of Human Nutrition. 2016;3(1):20-31.

15. Nasrul N, Maudu R, Hafid F. Trend And Prevalence Of Stunting In Children Under Two Years From 2007-2016 In Central Sulawesl. Preventif: Jurnal Kesehatan Masyarakat.8(2):73-8.

16. Siswatibudi H, Paramastri D, Lazuardi D. Facebook Messenger Sebagai Media Promosi Kesehatan Reproduksi Remaja Studi Di Smp Muhammadiyah Depok Sleman Yogyakarta: Doctoral dissertation. Yogyakarta: Universitas Gadjah Mada; 2016.

17. Devi ES. Pengaruh Penyuluhan Media Audio Visual Video Terhadap Tingkat Pengetahuan Pemeriksaan Payudara Sendiri (Sadari) Pada Kader Posyandu di Tejokusuman Rw. 04 Notoprajan Yogyakarta: STIKES'Aisyiyah Yogyakarta; 2013.

18. Houts PS, Doak CC, Doak LG, Loscalzo MJ. The role of pictures in improving health communication: a review of research on attention, comprehension, recall, and adherence. Patient education and counseling. 2006;61(2):173-90.

19. Wu Y-C, Hsieh L-F, Lu J-J. What's The Relationship between Learning Satisfaction and Continuing Learning Intention? Procedia-Social and Behavioral Sciences. 2015;191:2849-54.

20. Putu FY, I Ketut A, I Nyoman Gede S. Efektifitas penggunaan media cetak dan media elektronika dalam promosi kesehatan terhadap peningkatan pengetahuan dan perubahan sikap siswa SD. JKL (Jurnal Kesehatan Lingkungan). 2014;4(1):29-39. 